\title{
Biochemical Characterization of Novel Lignans Isolated from the Wood of Taxus yunnanensis as Effective Stimulators for Glycogen Synthase Kinase- $3 \beta$ and the Phosphorylation of Basic Brain Proteins by the Kinase in Vitro
}

\author{
Kenzo Ohtsuki, ${ }^{* a}$ Sayaka Miyai, ${ }^{a}$ Akira Yamaguchi, ${ }^{a}$ Kouhei Morikawa, ${ }^{b}$ and Tetsuroh Okano ${ }^{b}$ \\ ${ }^{a}$ Laboratory of Molecular Signal Biology, Graduate School of Medical Sciences, Kitasato University: and \\ ${ }^{b}$ Laboratory of Complement Medicine, School of Allied Health Science, Kitasato University; 1-15-1 Kitasato, \\ Sagamihara, Minami-ku, Kanagawa 252-0373, Japan \\ Received October 8, 2011; accepted November 28, 2011; published online December 22, 2011
}

The stimulatory and inhibitory effects of several compounds and lignans isolated from the water extract of Taxus yunnanensis on the phosphorylation of three functional brain proteins (bovine myelin basic protein (bMBP), recombinant human tau protein (rhTP) and rat collapsin response mediator protein-2 (rCRMP-2))

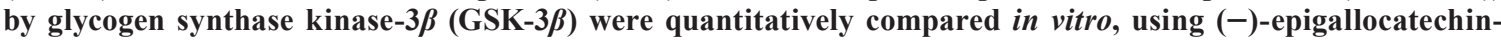
3-gallate [(-)EGCG] as a positive control. We found that (i) three selected Taxus lignans [(3S,4R)-4'-hydroxy6,3'-dimethoxyisoflavan-4-ol,(7R)-7-hydroxytaxiresinol and tanegool] highly stimulated the autophosphorylation of GSK-3 $\beta$ and the GSK-3 $\beta$-mediated phosphorylation of two basic brain proteins [bMBP (pI=11.3) and rhTP $(\mathrm{p} I=8.2)]$, but inhibited dose-dependently the phosphorylation of an acidic protein $(\mathrm{rCRMP}-2, \mathrm{p} I=6.0)$ by the kinase; (ii) these three Taxus lignans showed binding-affinities with bMBP as well as rhTP, but had low affinities with rCRMP-2; (iii) the binding of tanegool and (7R)-7-hydroxytaxiresinol to these two basic proteins induced their novel potent phosphorylation sites for GSK-3 $\beta$; and (iv) these three Taxus lignans, but not EGCG, induced Tyr-phosphorylation of GSK-3 $\beta$ in vitro. These results provided here suggest that (i) these three Taxus lignans act as novel effective activators for GSK-3 $\beta$ and the GSK-3 $\beta$-mediated phosphorylation of their binding basic proteins (rhTP and bMBP); and (ii) tanegool $\left(\mathrm{IC}_{50}=1 \mu \mathrm{M}\right)$ is an effective inhibitor for the phosphorylation of rCRMP-2 by the kinase in vitro.

Key words Taxus lignan; glycogen synthase kinase-3 $\beta$; stimulatory effect; protein phosphorylation

Recently, we reported that (i) plant polyphenol epigallocatechin-3-gallate (EGCG), not quercetin and luteolin, highly stimulates the phosphorylation of human recombinant tau protein (hrTP, $\mathrm{p} I=8.2$ ) and bovine myelin basic protein (bMBP, $\mathrm{p} I=11.3$ ) by glycogen synthase kinase-3 $\beta$ (GSK-3 $\beta$ ); (ii) EGCG has a binding-affinity with rhTP as well as bMBP; and (iii) the direct binding of EGCG to these two basic brain proteins (bMBP and rhTP) induces their novel potent phosphorylation sites for GSK-3 $\beta$, and leads to highly stimulate their phosphorylation by the kinase in vitro. ${ }^{1)}$ Also, we previously reported that phosphatidylinositol (PI) and two sulfated lipids [sulfatide and heparin $(\mathrm{SH})$ ] function as effective stimulators for the autophosphorylation of GSK-3 $\beta$ and the GSK-3 $\beta$-mediated phosphorylation of SH-binding proteins in vitro. ${ }^{2)}$ From these previous reports, ${ }^{1,2)}$ we conclude that both EGCG and SH may function as effective stimulators for the GSK-3 $\beta$-mediated phosphorylation of these two basic brain proteins (bMBP and rhTP), containing multiple potent phosphorylation sites for the kinase in vitro. ${ }^{1,2)}$

Glycogen synthase kinase 3 (GSK-3) is a constitutively active, proline-directed serine (Ser)/threonine (Thr) protein kinase encoded by two isoforms [GSK-3 $\alpha$ (approx. $51 \mathrm{kDa}$ ) and GSK-3 $\beta$ (approx. $47 \mathrm{kDa}, \mathrm{p} I=8.98$ )], which possess similar biochemical characteristics and substrate specificities. ${ }^{3-5)}$ GSK-3 is originally identified as a protein kinase that preferentially phosphorylates the rate-limiting enzyme, glycogen synthase (GS), in glycogen synthesis. ${ }^{6,7)}$ Further detailed characterization of GSK- $3 \beta$ revealed that (i) the kinase has a wide array of substrates, including cytoplasmic enzymes, nuclear transcriptional factors and signal-mediating molecules; (ii) the phosphorylation of Tyr-216 on GSK-3 $\beta$ is essential for the kinase activity; $\left.{ }^{8}\right)$ and (iii) GSK-3 $\beta$ plays an important physiological role in the regulation of numerous signaling pathways involved in cell differentiation and the morphological development of neurons. ${ }^{9)}$

Taxus yunnanensis CHeng et L.K. Fu, which belongs to the plant family Taxaceae, is widely distributed in Yunnan Province of the People's Republic of China and is commonly known as "Yunnan Hongdoushan." The wood of Taxus yunnanensis has been used in traditional Chinese medicine by several ethnic societies in the Yunnan Province for the treatment of kidney problems and diabetic conditions. The Kadota research group (Toyama Univ., Toyama, Japan) has characterized and identified many novel active compounds isolated from the water-extract of Taxus yunnanensis. ${ }^{10-16)}$ Recently, they reported a novel isoflavans [compound 1 (A)], a novel degraded compound 2 (B) from compound 4 (isotaxiresinol)] and a novel lignan compound $\mathbf{3}(\mathrm{C})$, which significantly inhibit the activity of cytochrome P450-3A4 in vitro. ${ }^{17)}$ Compound 6 (E) is identified as a known lignin of tanegool. ${ }^{18)}$ Since several Taxus compounds have been characterized to exhibit antioxdant, anti-inflammatory and neuroprotective effects, ${ }^{10-16)}$ we preliminarily tested the effects of at least 15 Taxus compounds, including five novel Taxus lignans (compounds $\mathrm{A}-\mathrm{E}$ ) on the GSK-3 $\beta$-mediated phosphorylation of three brain proteins [bMBP, rhTP and rat collapsin response mediator protein-2 (rCRMP-2, $\mathrm{p} I=6.0)$ ] in vitro. By our preliminary screening, five Taxus compounds (A-E) exhibiting significant stimulatory effects on the GSK- $3 \beta$-mediated phosphorylation of two basic proteins (bMBP and rhTP) were selected and fur- 
ther biochemically characterized in vitro.

The present study has been carried out to (i) determine the effects of two novel Taxus lignans (compounds A and C) and compound E (tanegool), in comparison with EGCG, on the autophosphorylation of GSK- $3 \beta$ and the phosphorylation of two basic proteins (bMBP and rhTP) and an acidic protein (rCRMP-2) by the kinase; (ii) characterize the Taxus compound-induced novel potent phosphorylation sites for GSK-3 $\beta$ on these two basic proteins; and (iii) determine the autophosphorylation kinetics of GSK-3 $\beta$ in the presence or absence of tanegool in vitro.

\section{MATERIALS AND METHODS}

Chemicals $\left[\gamma_{-}{ }^{32} \mathrm{P}\right]$ ATP $(111 \mathrm{TBq} / \mathrm{mmol})$ was obtained from Perkin Elmer Inc. (MA02451, U.S.A.); dithiothreitol (DTT) from Wako (Osaka, Japan); ECL detection reagent from GE healthcare UK Ltd. (Amersham Place, U.K.); (-)epigallocatechin gallate $[(-) \mathrm{EGCG}]$, bovine serum albumin (BSA) from Sigma Aldrich (St. Louis, U.S.A.); trypsin from Promega Co. (Madison, U.S.A.); and tyrosine-kinase inhibitor (PP2) from Alexis Biochemicals (New York, U.S.A.)

Protein Kinases and Two Effective Substrate Proteins (bMBP and hrTP) for GSK-3 $\beta$ Rabbit GSK-3 $\beta$ (rabbit muscle, specific activity: $14629 \mathrm{units} / \mathrm{mg}$ ) and purified bovine myelin basic protein (bMBP) were obtained from Sigma Aldrich (St. Louis, U.S.A.); and recombinant human tau protein (rhTP) from Calbiochem (San Diego, U.S.A.). Rat recombinant CK1 $\delta$ (specific activity: $17500 \mathrm{units} / \mathrm{mg}$ ) was obtained from Promega Co. (Madison, U.S.A.).

Extraction, Isolation and Identification of Taxus Compounds The wood of Taxus yunnanensis was chopped into small pieces and crushed into a powder. The dried wood powder (approx. $75 \mathrm{~g}$ ) was extracted with $\mathrm{H}_{2} \mathrm{O}$ under reflux for $45 \mathrm{~min}$ to yield the $\mathrm{H}_{2} \mathrm{O}$ extract (approx. 51.0 g). The residue was further extracted with $\mathrm{H}_{2} \mathrm{O} / \mathrm{MeOH}$ and $\mathrm{MeOH}$ to give the $\mathrm{H}_{2} \mathrm{O} / \mathrm{MeOH}(1: 1)$ and the $\mathrm{MeOH}$ extracts (approx. $7.5 \mathrm{~g}$ each), respectively. Three partially purified fractions (F-I, F-II and F-III), containing novel compounds (A-D) and tanegool, were prepared from the aqueous extract of Taxus yunnanensis. Finally, the chemical structures of at least 12 compounds (112) from the three Taxus fractions were identified. ${ }^{17)}$ From our preliminary experiments using in vitro kinase assay, at least five effective compounds: compound 1 (A) identified as a novel isoflavan [(3S,4R)-4'-hydroxy-6,3'-dimethoxyisoflavan-4-ol] degraded from isotaxiresinol, compound 2 (B) as a novel lignan, [2,3-bis(hydroxymethyl)-7-hydroxy-6-methoxy-tetralone] degraded from compound 4 (isotaxiresinol), compound 3 (C) as a novel lignan [(7R)-7-hydroxytaxiresinol] ${ }^{17)}$ compound 6 (E) as a known lignan (tanegool), ${ }^{18)}$ and compound 12 (D), ${ }^{19}$ as a known $\alpha$-conidendrin, were selected from 15 Taxus compounds, including secoisolariciresinol, isotaxiresinol and taxiresinol.

Purification of CRMP-2 from Rat Brain as an Effective Substrate for GSK-3 $\boldsymbol{\beta}$ CRMP-2 was highly purified from the extract of rat brain by means of successive DEAEcellulose column chromatography, gel filtration of a SDX 200 pg column and heparin-affinity column chromatography. Finally, CRMP-2 (70 kDa polypeptide, p70) in the heparinaffinity fraction was purified by Mono Q column chromatography as a single polypeptide, as previously reported. ${ }^{1)}$
Assay for GSK-3 $\beta$ Activity in Vitro Three protein substrates (bMBP, rhTP and rCRMP: approx. $2 \mu \mathrm{g}$ each) were separately incubated for $30 \mathrm{~min}$ at $30^{\circ} \mathrm{C}$ in the reaction mixtures $(50 \mu \mathrm{L})$ comprising GSK-3 $\beta$ (approx. 50 ng), $40 \mathrm{~mm}$ Tris$\mathrm{HCl}(\mathrm{pH} 7.6), 2 \mathrm{~mm}$ DTT, $3 \mathrm{~mm} \mathrm{Mn}^{2+}$ and $5 \mu \mathrm{M}\left[\gamma_{-}{ }^{32} \mathrm{P}\right] \mathrm{ATP}$ $(500 \mathrm{cpm} / \mathrm{pmol})$ in the presence or absence of the indicated Taxus compounds. ${ }^{32} \mathrm{P}$-Labeled substrate proteins in the reaction mixtures were separately detected by autoradiography after protein analysis by sodium dodecylsulfate-polyacrylamide gel electrophoresis (SDS-PAGE). The protein phosphorylation by GSK- $3 \beta$ was terminated by the addition of $0.5 \mathrm{~mL} 20 \%$ trichloroacetic acid (TCA) and $0.25 \mathrm{~mL} 0.1 \mathrm{M}$ sodium pyrophosphate containing bovine serum albumin (BSA) $(1 \mathrm{mg} / \mathrm{mL})$ and $10 \mathrm{~mm}$ ethylene diaminetetraacetic acid (EDTA). The TCAinsoluble precipitates were trapped on a glass membrane filter (Advantec GF/75), and then washed successively with 2\% TCA and $100 \%$ ethanol. After drying, the ${ }^{32}$ P-radioactivity on the membrane filter was measured with a liquid scintillation spectrophotometer, as described in our previous reports. ${ }^{1,2)}$

Phosphopeptide Mapping Briefly, either bMBP or rhTP (approx. $2 \mu \mathrm{g})$ in reaction mixtures $(50 \mu \mathrm{L})$ comprising $40 \mathrm{~mm}$ Tris- $\mathrm{HCl}$ (pH 7.6), $2 \mathrm{~mm}$ DTT, $3 \mathrm{~mm} \mathrm{Mn}{ }^{2+}, 5 \mu \mathrm{M}\left[\gamma^{32} \mathrm{P}\right]$ ATP $(500 \mathrm{cpm} / \mathrm{pmol})$ and GSK-3 $\beta$ (approx. 50 ng) in the absence or presence of one of three Taxus compounds (A, C and E) were incubated with GSK-3 $\beta$ (approx. $50 \mathrm{ng}$ ) for $120 \mathrm{~min}$ at $30{ }^{\circ} \mathrm{C}$. ${ }^{32} \mathrm{P}$-Labeled bMBP or rhTP digested by trypsin in the reaction mixtures was analyzed by TLC electrophoresis under the conditions of $40 \mathrm{~mA}$ for $60 \mathrm{~min}$ (first dimension) and chromatography (second dimension). Separated ${ }^{32} \mathrm{P}$-labeled fragments cleaved from bMBP or rhTP were detected by autoradiography. ${ }^{2,20)}$

Measurement of the Binding Affinities of Three Taxus Lignans with Three Substrate Proteins by a Quartz Crystal Microbalance (QCM) The binding affinities of three substrate proteins (bMBP, rhTP and rCRMP-2) with one of three Taxus compounds (A, C and E) in comparison with EGCG were separately determined with a QCM (Initium, Tokyo, Japan) using BSA as an negative control, as described in our previous reports. ${ }^{2,20)}$

\section{RESULTS}

The Stimulatory Effects of Three Selected Taxus Compounds (A, C and E) on the GSK-3 $\beta$-Mediated Phosphorylation of Three Brain Proteins in Vitro To determine the stimulatory effects of three selected Taxus compounds (A, C and E) on the GSK- $3 \beta$-mediated phosphorylation of rhTP, this protein substrate (approx. $3 \mu \mathrm{g}$ ) was incubated for $30 \mathrm{~min}$ at $30^{\circ} \mathrm{C}$ with GSK-3 $\beta$ (approx. $50 \mathrm{ng}$ ) and $5 \mu \mathrm{M}$ $\left[\gamma-{ }^{32} \mathrm{P}\right]$-ATP $(500 \mathrm{cpm} / \mathrm{pmol})$ in the presence of the indicated concentrations of one of the three Taxus compounds in vitro. ${ }^{32} \mathrm{P}$-Labeled rhTP in the reaction mixtures was detected by autoradiography after SDS-PAGE. As shown in Fig. 2, it was found that (i) these three Taxus compounds highly stimulated the GSK-3 $\beta$-mediated phosphorylation of rhTP; and (ii) the maximum phosphorylation of rhTP by GSK-3 $\beta$ was observed when incubated with these three Taxus compounds at approx. $10 \mu \mathrm{M}$. Under the same assay conditions, taxiresinol, but not isotaxiresinol and secoisolariciresinol, significantly stimulated the GSK-3 $\beta$-mediated phosphorylation of rhTP in vitro (data not shown). In the presence of these three Taxus compounds 
<smiles>COc1ccc2c(c1)[C@H](O)[C@H](C1CCC(O)C(OC)C1)CC2</smiles>

A<smiles>COc1cc2c(cc1O)C(=O)[C@H](CO)[C@H](CO)C2</smiles>

B<smiles>COc1cc([C@@H](O)[C@H]2CO[C@@H](c3ccc(O)c(OC)c3)[C@H]2CO)ccc1O</smiles><smiles>COc1cc([C@@H](O)[C@H]2CO[C@@H](c3ccc(O)c(O)c3)[C@H]2CO)ccc1O</smiles><smiles>COc1cc([C@@H]2c3cc(O)c(OC)cc3C[C@H]3C(=O)OC[C@@H]32)ccc1O</smiles><smiles>O=C(O[C@H]1Cc2c(O)cc(O)cc2C[C@H]1c1cc(O)c(O)c(O)c1)c1ccc(O)c(O)c1</smiles>

(-) EGCG

Fig. 1. The Chemical Structures of Five Selected Taxus Compounds (A-E) and (-)EGCG

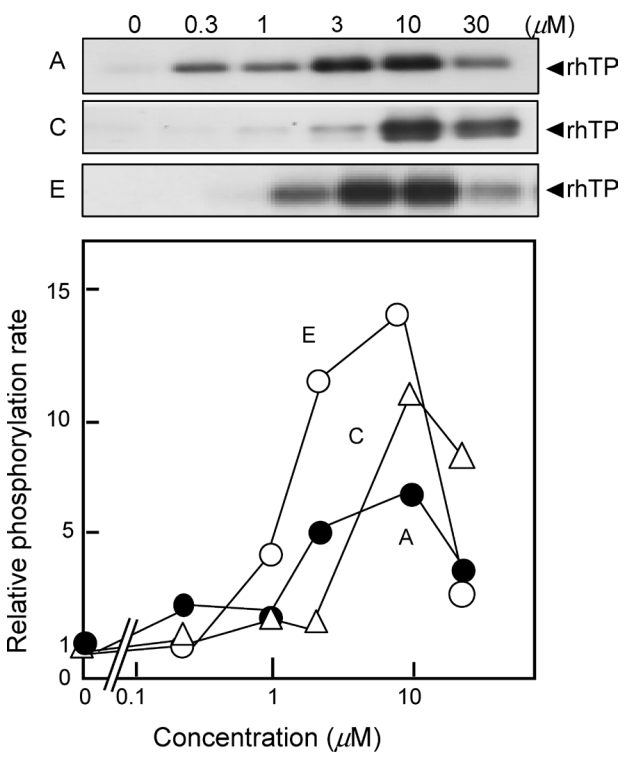

Fig. 2. The Stimulatory Effects of Three Selected Taxus Compounds (A, C, E) on the GSK-3 $\beta$-Mediated Phosphorylation of rhHTP in Vitro

After incubation for $30 \mathrm{~min}$ at $30^{\circ} \mathrm{C}$ in the presence of the indicated concentrations of three selected Taxus compounds (A, C, E), ${ }^{32} \mathrm{P}$-labeled rhTP in the reaction mixtures was detected by autoradiography after SDS-PAGE. The rate 1 represents the phosphorylation of rhTP by GSK-3 $\beta$ in the absence of these three Taxus compounds in vitro. Compound $\mathrm{A}(\mathbf{O})$; compound $\mathrm{C}(\triangle)$; and compound $\mathrm{E}(\mathrm{O})$.

(A, C and E) at $10 \mu \mathrm{M}$, GSK- $3 \beta$ preferentially phosphorylated Ser-residues rather than Thr-residues on rhTP (Fig. 3).

The stimulatory and inhibitory effects of these three Taxus compounds on the GSK- $3 \beta$-mediated phosphorylation of bMBP $(\mathrm{p} I=11.3)$ and $\mathrm{rCRMP}-2(\mathrm{p} I=6.0)$ were separately determined in vitro. As shown in Fig. 4, it was found that (i) compound $\mathrm{E}$ stimulated 5.3-fold the GSK-3 $\beta$-mediated phosphorylation of bMBP, as compared without the Taxus compound; (ii) the stimulatory effect of compound $\mathrm{C}$ on the phosphorylation of bMBP by the kinase was similar to that observed with EGCG; and (iii) this phosphorylation was significantly stimulated by compound $\mathrm{A}$ in vitro. In the case of rCRMP-2, two Taxus compounds (A and C) at $10 \mu \mathrm{M}$ inhibited more that $90 \%$ of the GSK-3 $\beta$-mediated CRMP-2 phosphorylation (Fig. 5). The $\mathrm{IC}_{50}$ (approx. $1 \mu \mathrm{M}$ ) of compound $\mathrm{E}$ on the
GSK-3 $\beta$-mediated phosphorylation of CRMP-2 was about 5 -fold higher than that (approx. $0.2 \mu \mathrm{M}$ ) of EGCG in vitro. The $\mathrm{IC}_{50}$ of taxiresinol on the GSK- $3 \beta$-mediated phosphorylation of rCRMP-2 was similar to that $\left(\mathrm{IC}_{50}=\right.$ approx. $\left.3 \mu \mathrm{M}\right)$ of compound $\mathrm{A}$ in vitro. These results show that compound $\mathrm{E}$ among tested Taxus compounds acts as an effective stimulator for the GSK- $3 \beta$-mediated phosphorylation of two basic proteins (rhTP and $\mathrm{bMBP}$ ) and a potent inhibitor for the phosphorylation of an acidic protein (rCRMP-2) by the kinase in vitro.

The Stimulatory Effects of Three Taxus Compounds on the Autophosphorylation of GSK-3 $\beta$ in Vitro To determine the stimulatory effects of the three Taxus compounds and EGCG on the autophosphorylation of GSK-3 $\beta$ in vitro, the kinase was directly incubated with $5 \mu \mathrm{M}\left[\gamma_{-}{ }^{32} \mathrm{P}\right] \mathrm{ATP}(500 \mathrm{cpm} /$ pmol) in the presence of one of the three Taxus compounds or EGCG. As shown in Fig. 6, it was found that (i) compound E at $3 \mu \mathrm{M}$ increased approx. 6.3-hold the autoposphorylation of GSK- $3 \beta$; and (ii) compounds $\mathrm{A}$ at $10 \mu \mathrm{M}$ and compound $\mathrm{C}$ at $3 \mu \mathrm{M}$ also highly stimulated the autophosphorylation of GSK$3 \beta$, but not significantly with $1 \mu \mathrm{M}$ EGCG. In the presence of $3 \mu \mathrm{M}$ compound E, Thr-residues in comparison with Serresidues on GSK-3 $\beta$ were preferentially phosphorylated (Fig. 7). Interestingly, significant Tyr-phosphorylation of GSK-3 $\beta$ was detected when incubated with $3 \mu \mathrm{M}$ compound E (Fig. 7). Similar Tyr-phosphorylation of GSK-3 $\beta$ was observed with the other two Taxus compounds (A and C), but not with EGCG. As expected, PP2 (Tyr-kinase inhibitor) at $2 \mu \mathrm{M}$ inhibited approx. $90 \%$ of the compound E-induced high autophosphorylation of GSK- $3 \beta$ in vitro. These results clearly show that the direct binding of these three Taxus compounds, not EGCG, to GSK-3 $\beta$ may induce the high autophosphorylation and Tyrphosphorylation by the kinase in vitro.

The autophosphorylation kinetics of GSK- $3 \beta$ were determined in the induce Tyr-phosphorylation of the kinase presence or absence of either compound E $(3 \mu \mathrm{M})$ or $1 \mu \mathrm{M}$ EGCG in vitro. No significant change was observed the apparent $K_{\mathrm{m}}$ value (control: $0.70 \mu \mathrm{M}$ ) of ATP for GSK-3 $\beta$ in the autophosphorylation of the kinase in the presence of $3 \mu \mathrm{M}$ compound E, whereas the $V_{\max }$ value of ATP for GSK-3 $\beta$ shifted to 4.2 from $0.47 \mu \mathrm{mol} / \mathrm{mg} / \mathrm{min}$ (Fig. 8). In contrast, the apparent $V_{\max }$ value of ATP for GSK-3 $\beta$ shifted to 1.0 from $0.45 \mu \mathrm{mol} / \mathrm{mg} /$ min when incubated with $1 \mu \mathrm{M}$ EGCG (Fig. 8). These results 
(a) None

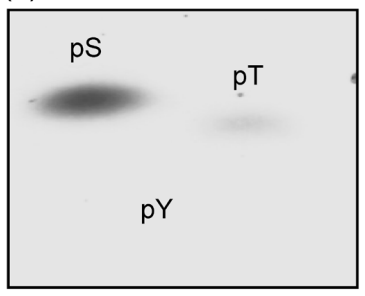

(b) $\mathrm{A}$

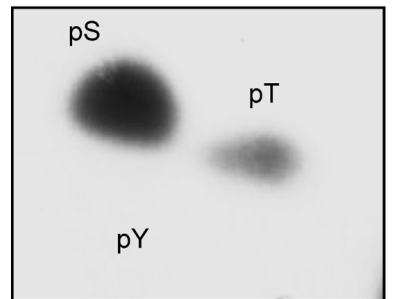

(c) $\mathrm{C}$

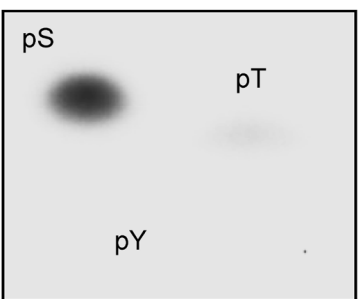

(d) $\mathrm{E}$

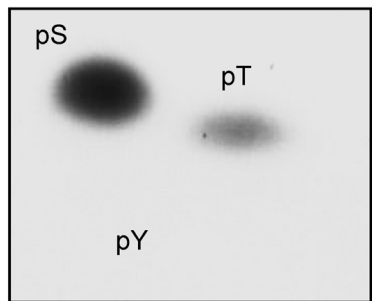

Fig. 3. Detection of Phosphoamino Acids on rhTP Fully Phosphorylated by GSK-3 $\beta$ in the Presence of Three Taxus Compounds (A, C, E) in Vitro

The ${ }^{32} \mathrm{P}$-Labeled phosphoamino acids of rhTP fully phosphorylated by GSK- $3 \beta$ in the absence or presence of either compound A, compound $\mathrm{C}$ or compound $\mathrm{E}$ at $10 \mu \mathrm{M}$ were separately detected by autoradiography after two-dimensional TLC electrophoresis, as described in Materials and Methods.

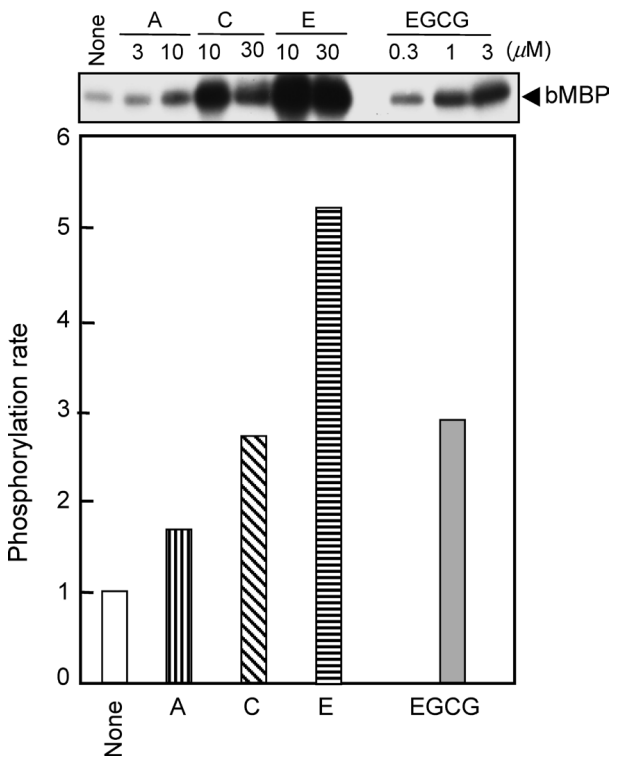

Fig. 4. The Stimulatory Effects of Three Taxus Compounds (A, C, E) and EGCG on the GSK-3 $\beta$-Mediated Phosphorylation of bMBP in Vitro

After preincubation for $10 \mathrm{~min}$ at $30^{\circ} \mathrm{C}$ with GSK-3 $\beta$ (approx. $50 \mathrm{ng}$ ) and $5 \mu \mathrm{m}$ $\left[\gamma_{-}{ }^{32} \mathrm{P}\right]$ ATP $(500 \mathrm{cpm} / \mathrm{pmol})$ with the indicated concentrations of one of three Taxus compounds, bMBP was added to the reaction mixtures, and then further incubated for $30 \mathrm{~min}$ at $30^{\circ} \mathrm{C} .{ }^{32} \mathrm{P}$-Labeled bMBP in the reaction mixtures was detected by autoradiography after SDS-PAGE. The rate 1 represents the phosphorylation of bMBP by GSK- $3 \beta$ in the absence of these three Taxus compounds in vitro. Compound A at $10 \mu \mathrm{m} ; 10 \mu \mathrm{m}$ compound $\mathrm{C} ; 10 \mu \mathrm{m}$ compound $\mathrm{E}$ and $3 \mu \mathrm{M}$ EGCG.

show that the direct binding of compound E to GSK-3 $\beta$ highly stimulates the autophosphorylation of the kinase and an increase in the $V_{\max }$ value of ATP for the kinase in vitro.

Detection of the Taxus Compound-Induced Novel Potent Phosphorylation Sites for GSK-3 $\beta$ on $\mathbf{r h T P}$ and bMBP in Vitro To further characterize the Taxus compound-induced high phosphorylation of rhTP by GSK- $3 \beta$ in vitro, phosphopeptide-mapping was performed after rhTP was incubated for $120 \mathrm{~min}$ at $30^{\circ} \mathrm{C}$ with GSK-3 $\beta$ (approx. 50 ng) and $5 \mu \mathrm{M}\left[\gamma^{-}-{ }^{32} \mathrm{P}\right]$ ATP $(500 \mathrm{cpm} / \mathrm{pmol})$ in the absence of presence of one of the three Taxus compounds or EGCG. ${ }^{32}$ P-Fragments degraded from ${ }^{32} \mathrm{P}$-labeled rhTP were subjected to SDS-PAGE, after exhaustive in gel digestion of the rhTP-band with trypsin. Autoradiography (Fig. 9) detected four phosphorylated fragments (spots 1-4) and seven minor spots (spots: $\mathrm{a}-\mathrm{g}$ ), which were clearly different from the phosphopeptide pattern observed with EGCG, when the phosphorylation of rhTP by GSK-3 $\beta$ was carried out in the presence of one of these three Taxus compounds at $10 \mu \mathrm{M}$ in vitro. Similar analysis of bMBP fully phosphorylated by GSK-3 $\beta$ in the absence of presence of these Taxus compounds was carried out. Autoradiography (Fig. 10) detected three phosphorylated fragments (spots: 1-3) degraded from bMBP fully phosphorylated without these Taxus compounds in vitro. In contrast, three major spots and two minor spots ( $a$ and $b$ ) were detected when full phosphorylation of bMBP by GSK- $3 \beta$ was carried out in the presence of either compound $\mathrm{A}$ or compound $\mathrm{C}$ at $10 \mu \mathrm{M}$ (Fig. 10). Furthermore, three major spots and three-minor spots ( $\mathrm{a}, \mathrm{b}$ and $\mathrm{c}$ ) were detected when bMBP was fully phosphorylated by GSK- $3 \beta$ in the presence of $10 \mu \mathrm{M}$ compound $\mathrm{E}$ in vitro (Fig. 10). These results show that (i) the direct incubation of two basic proteins (rhTP and bMBP) with these three Taxus compounds (A, C and E) may induce their novel potent phosphorylation sites for GSK-3 $\beta$; and (ii) these Taxus compoundinduced potent phosphorylation sites for GSK-3 $\beta$ are different from those observed with EGCG in vitro.

The Binding Affinities of the Three Taxus Compounds with bMBP, rhTP and rCRMP-2 in Vitro The above results (Figs. 9, 10) suggest that the direct bindings of these three Taxus compounds to two basic brain proteins (bMBP and rhTP) result in the induction of their high phosphorylation by GSK- $3 \beta$ in vitro. To confirm this, the binding affinities of these three Taxus compounds with three brain proteins (rhTP, bMBP and rCRMP-2) and EGCG were separately measured by a QCM. As expected, these three Taxus compounds directly bound to bMBP and rhTP, while they showed low binding affinities with rCRMP-2 (Fig. 11). EGCG had binding affinities with these two basic proteins, as previously reported. ${ }^{1)}$ However, the binding abilities of these three Taxus compounds with three protein substrates (bMBP, rhTP and rCRMP-2) did 

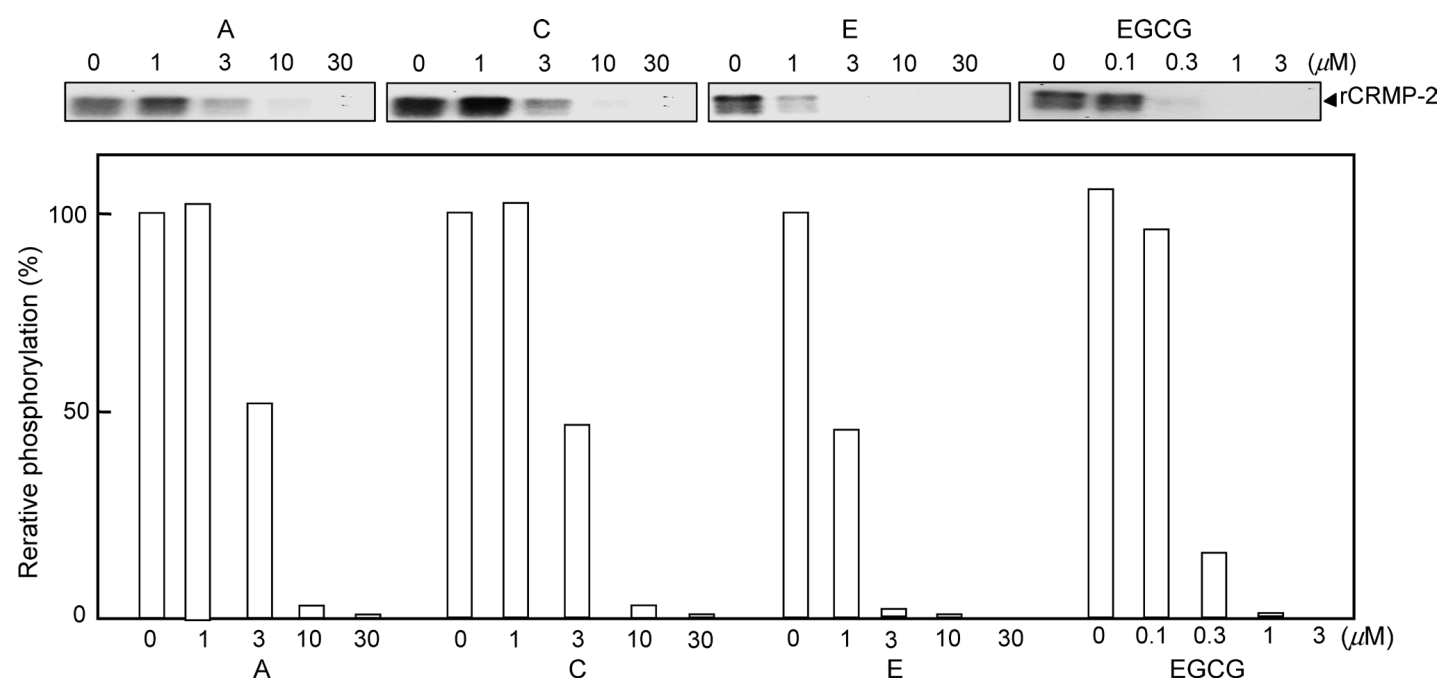

Fig. 5. The Inhibitory Effects of Three Taxus Compounds (A, C, E) and EGCG on the GSK-3 $\beta$-Mediated Phosphorylation of rCRMP-2 in Vitro

After incubation for $30 \mathrm{~min}$ at $30^{\circ} \mathrm{C}$ in the presence of the indicated concentrations of one of the three Taxus compounds (A, C, E) and EGCG, ${ }^{32} \mathrm{P}-1$ labeled $\mathrm{rCRMP}-2$ in the reaction mixtures was detected by autoradiography after SDS-PAGE. The rate 1 represents the phosphorylation of rCRMP-2 by GSK- $3 \beta$ in the absence of these Taxus compounds and EGCG in vitro.

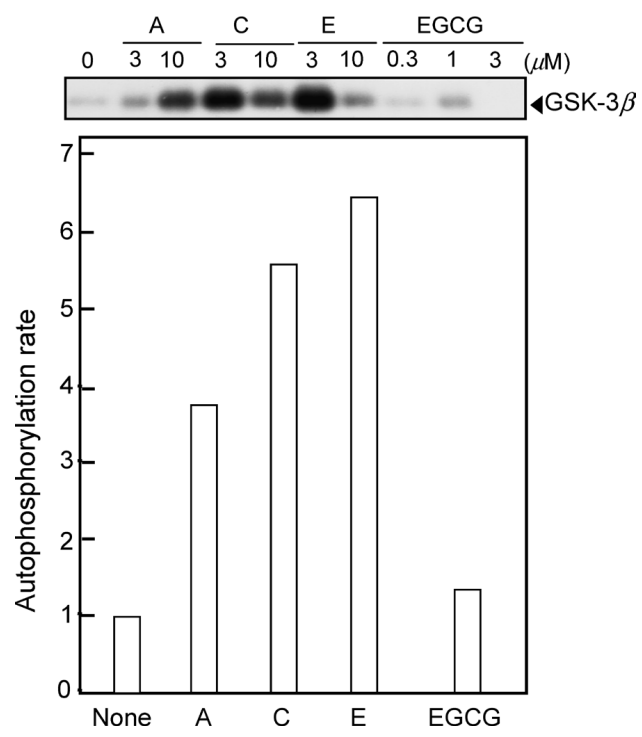

Fig. 6. The Stimulatory Effects of Three Taxus Compounds and EGCG on the Autophosphorylation of GSK- $3 \beta$ in Vitro

GSK- $3 \beta$ (approx. $50 \mathrm{ng}$ ) was directly incubated for $30 \mathrm{~min}$ at $30^{\circ} \mathrm{C}$ with $5 \mu \mathrm{m}$ $\left[\gamma-{ }^{32} \mathrm{P}\right]$ ATP $(500 \mathrm{cmp} / \mathrm{pmol})$ in the presence of the indicated concentrations of one of the three Taxus compounds (A, C, E) or EGCG. ${ }^{32}$ P-Labelled GSK-3 $\beta$ in the reaction mixtures was detected by autoradiography after SDS-PAGE. The rate 1 represents the autophosphorylation of GSK- $3 \beta$ in the absence of these three Taxus compounds in vitro. Compound A at $10 \mu \mathrm{M} ; 3 \mu \mathrm{m}$ compound C; $3 \mu \mathrm{m}$ compound $\mathrm{E}$ and $1 \mu \mathrm{m}$ EGCG. not correspond to their stimulatory and inhibitory effects on the GSK- $3 \beta$-mediated phosphorylation of these three protein substrates in vitro.

The High Stimulatory Effect of Compound $E$ on the GSK-3 $\beta$-Mediated Phosphorylation of rhTP Primed by CK1 $\delta$ in Vitro Previously, we reported that rhTP primed by casein kinase $1 \delta(\mathrm{CK} 1 \delta)$ functions as an effective phosphate acceptor for GSK-3 $\beta$ in vitro. ${ }^{21)}$ The stimulatory effect of compound $\mathrm{E}$ on the GSK- $3 \beta$-mediated phosphorylation of unprimed rhTP and rhTP primed by $\mathrm{CK} 1 \delta$ were compared in vitro. Compound $\mathrm{E}$ at $10 \mu \mathrm{M}$ stimulated about 1.9 -fold the GSK- $3 \beta$-mediated phosphorylation of primed by CK $1 \delta$ (lane 4 ) in comparison with unprimed rhTP (lane 3, Fig. 12). Under the same experimental conditions, similar stimulatory effects of other two Taxus compounds (A and C), but not with EGCG, on the GSK-3 $\beta$-mediated phosphorylation of rhTP primed by CK $1 \delta$ were observed. However, no significant effects of these three Taxus compounds on the CK1 $\delta$-mediated phosphorylation of rhTP and $\alpha$-casein were observed in vitro (data not shown). These results show that (i) rhTP primed by $\mathrm{CK} 1 \delta$ functions as an effective substrate for GSK-3 $\beta$; and (ii) compound E highly stimulates the GSK- $3 \beta$-mediated phosphorylation of $\operatorname{rhTP}$ by primed by $\mathrm{CK} 1 \delta$ in vitro. (a) None

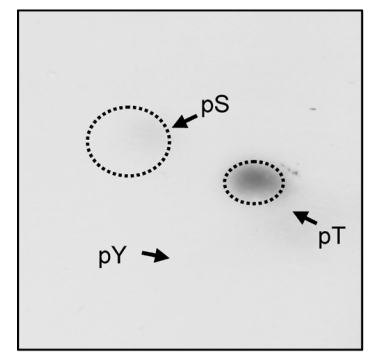

(b) $E$

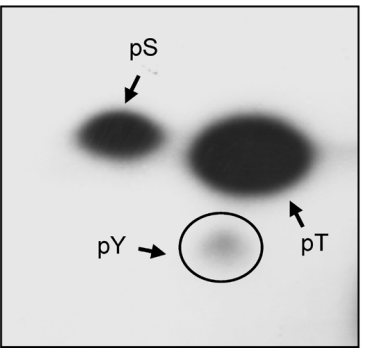

(c) EGCG

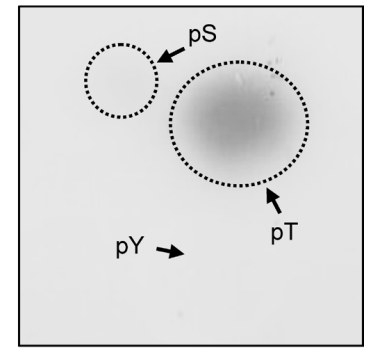

Fig. 7. Detection of Tyr-Phosphorylation on GSK-3 $\beta$ Autophosphorylated in the Presence of Compound E or EGCG in Vitro

GSK- $3 \beta$ (approx. $50 \mathrm{ng}$ ) was directly incubated for $30 \mathrm{~min}$ at $30^{\circ} \mathrm{C}$ with $5 \mu \mathrm{M}\left[\gamma^{-32} \mathrm{P}\right] \mathrm{ATP}(500 \mathrm{cmp} / \mathrm{pmol})$ in the absence or presence of either $3 \mu \mathrm{M}$ compound $\mathrm{E}$ or $1 \mu \mathrm{M}$ EGCG. ${ }^{32} \mathrm{P}$-Labeled phosphoamino acids of fully autophosphorylated GSK-3 $\beta$ were detected, as described in the legend of Fig. 3. 


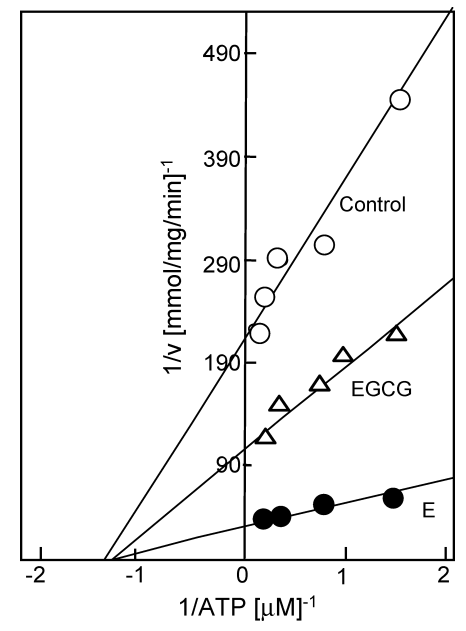

Fig. 8. Autophosphorylation Kinetics of GSK-3 $\beta$ in the Presence of Compound E in Vitro

The autophosphorylation kinetics for GSK- $3 \beta$ were determined by its incubation for $30 \mathrm{~min}$ at $30^{\circ} \mathrm{C}$ with the indicated concentrations of $\left[\gamma_{-}^{32} \mathrm{P}\right] \mathrm{ATP}$ in the presence or absence of either $3 \mu \mathrm{m}$ compound E or $1 \mu \mathrm{M}$ EGCG in vitro. ${ }^{32} \mathrm{P}$-Labelled GSK-3 $\beta$ in the reaction mixtures was determined by the membrane filter method, as described in the Materials and Methods. Lineweaver-Burk plots of ATP for GSK-3 $\beta$ in the absence $(\bigcirc)$ or presence of either $3 \mu \mathrm{m}$ compound $\mathrm{E}(\bullet)$ or $1 \mu \mathrm{M}$ EGCG $(\triangle)$.

\section{DISCUSSION}

The present in vitro biochemical characterization revealed that three selected Taxus lignans $\left[(3 S, 4 R)-4^{\prime}\right.$-hydroxy-6,3'dimethoxyisoflavan-4-ol (compound A), (7R)-7-hydroxytaxiresinol (compound C) and tanegool (compound E)] functioned as effective activators for GSK- $3 \beta$ and high stimulators for the GSK-3 $\beta$-mediated phosphorylation of two basic brain proteins (bMBP and rhTP), but not for an acidic protein (rCRMP-2). This conclusion is supported by evidence that (i) these three Taxus lignans induce the high autophosphorylation of GSK-3 $\beta$ (Fig. 6) and the GSK-3 $\beta$-mediated high phosphory- lation of these two basic proteins (Figs. 2, 4), but inhibit dosedependently the phosphorylation of rCRMP-2 by the kinase (Fig. 5); (ii) the direct bindings of these three Taxus lignans to rhTP and bMBP result in the induction of novel potent phosphorylation sites for the kinase on these two basic proteins (Figs. 9, 10); and (iii) these three lignans have binding affinities with bMBP and rhTP, but low binding affinities with rCRMP-2 in vitro (Fig. 11). Similar stimulatory and inhibitory effects on the GSK- $3 \beta$-mediated phosphorylation of bMBP (Fig. 4) and rCRMP-2 (Fig. 5), respectively, were observed with EGCG in vitro. However, the stimulatory effects of two Taxus lignans [tanegool and (7R)-7-hydroxytaxiresinol] on the autophosphorylation of GSK-3 $\beta$ are different from that observed with EGCG, because these two lignans, but not EGCG, cause the high autophosphorylation of GSK-3 $\beta$ through preferential phosphorylation of Thr-residues and the induction of Tyr-phosphorylation on the kinase in vitro (Fig. 7). Since it has been reported that the intramolecular autophosphorylation at Tyr-216 on GSK-3 $\beta$ is required for an activation of the kinase in vitro, ${ }^{22,23)}$ both tanegool and $(7 R)$-7-hydroxytaxiresinol may function as effective activators for GSK-3 $\beta$ through the induction of Tyr-phosphorylation and a significant increase in the $V \max$ value of ATP for the kinase in vitro.

Earlier studies concerning the biochemical characterization of high TP phosphorylation have revealed that (i) GSK- $3 \beta$ is characterized as a protein kinase responsible for hyperphosphorylation of TP in an early stage of human neurodegenerative disorder Alzheimer's disease (AD) ${ }^{23)}$; (ii) two CK1 isoforms $(\alpha$ and $\delta$ ) are tightly associated with neurofibrillary lesions ${ }^{24)}$; (iii) cellular $\mathrm{CK} 1 \delta$ is highly elevated in $\mathrm{AD}$ brain $^{25)}$; and (iv) the GSK-3 $\beta$-mediated high phosphorylation of TP induces synapse loss and neuronal death through the formation of neurofibrillary tangle with highly phosphorylated TP. ${ }^{26}$ ) As expected, we confirmed that two Taxus lignans [tanegool and (7R)-7-hydroxytaxiresinol] significantly stimulated the GSK- $3 \beta$-mediated phosphorylation of rhTP primed by $\mathrm{CK} 1 \delta$
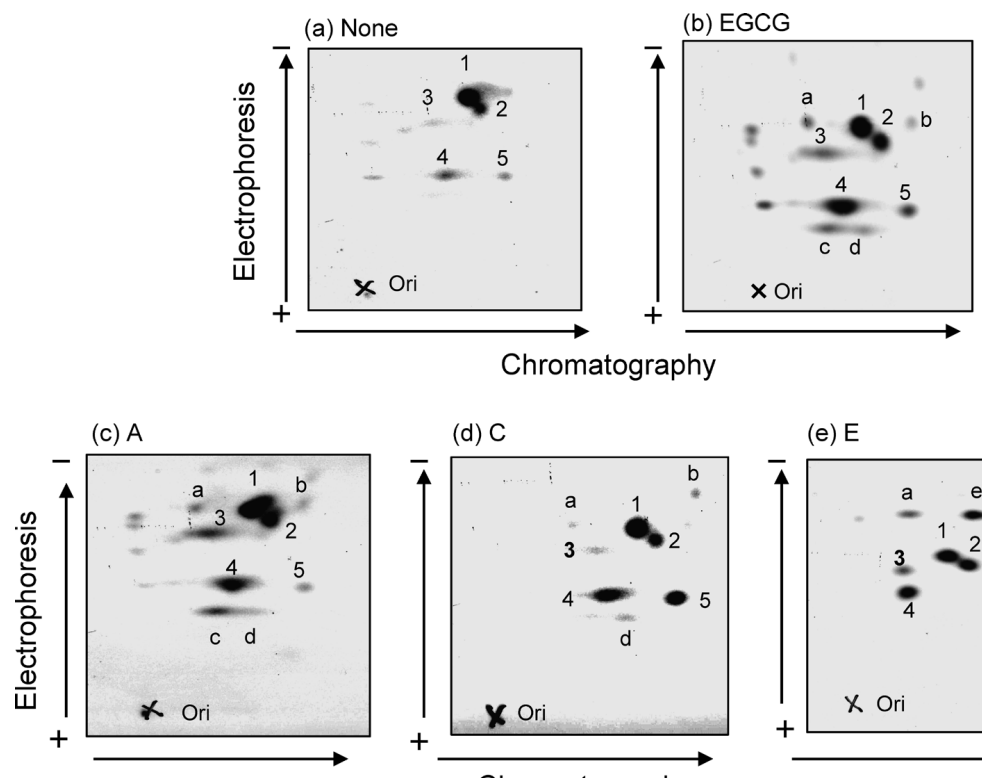

(d) C

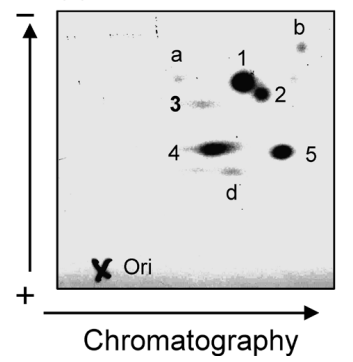

(e) $E$

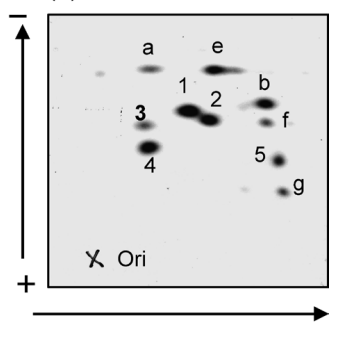

Fig. 9. Peptide Mapping of rhTP Fully Phosphorylated by GSK-3 $\beta$ in the Presence of One of the Three Taxus Compounds or EGCG in Vitro

After hrTP (approx. $2 \mu \mathrm{g}$ ) was incubated for $120 \mathrm{~min}$ at $30^{\circ} \mathrm{C}$ with GSK-3 $\beta$ (approx. $50 \mathrm{ng}$ ) and $5 \mu \mathrm{M}\left[\gamma_{-}{ }^{32} \mathrm{P}\right] \mathrm{ATP}(500 \mathrm{cpm} / \mathrm{pmol}$ ) in the presence of either $10 \mu \mathrm{M} \mathrm{compound}$ A, $10 \mu \mathrm{m}$ compound $\mathrm{C}, 10 \mu \mathrm{M}$ compound $\mathrm{E}$ or $3 \mu \mathrm{M}$ EGCG, ${ }^{32} \mathrm{P}$-labelled rhTP was digested with trypsin in the gel, the resulting fragments were analyzed and detected, as described in the legend of Fig. 3. 

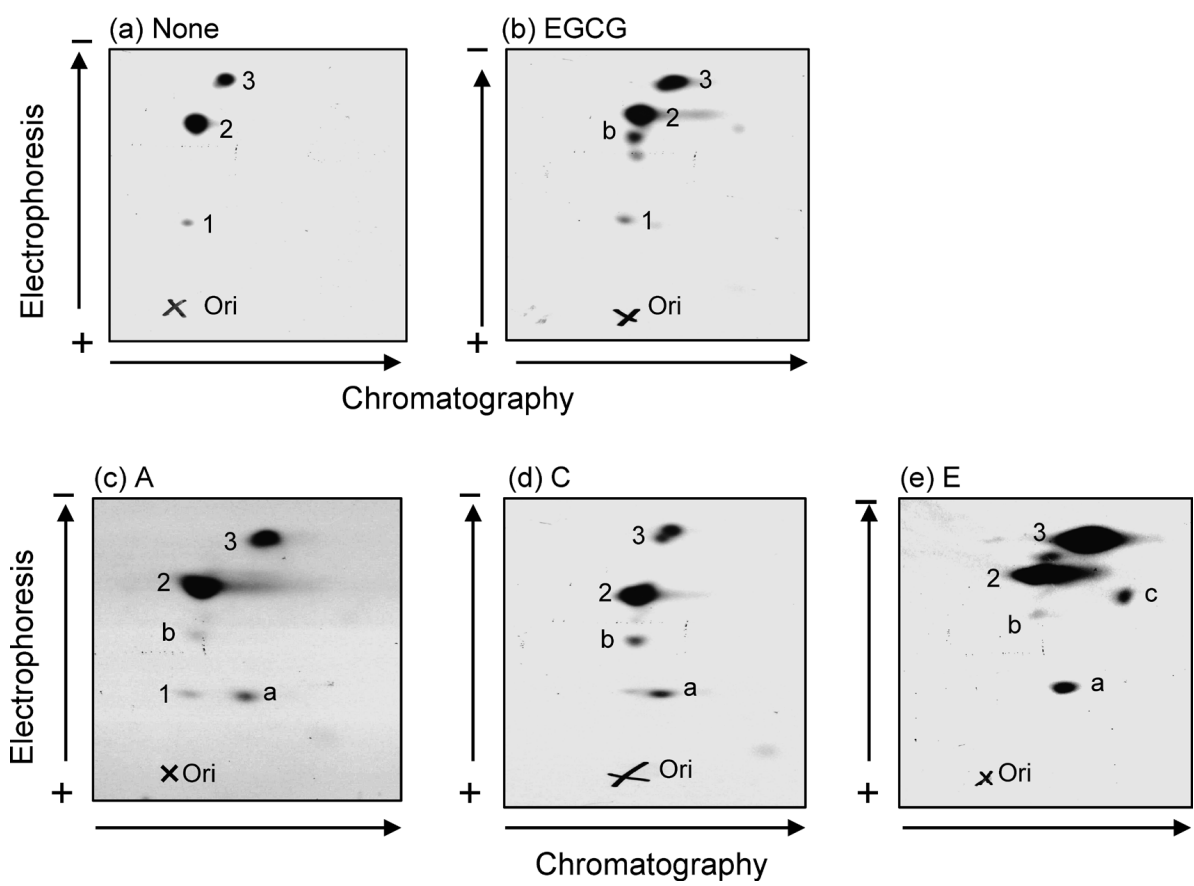

Fig. 10. Peptide Mapping of bMBP Fully Phosphorylated by GSK-3 $\beta$ in the Presence of One of the Three Taxus Compounds in Vitro

After bMBP (approx. $2 \mu \mathrm{g}$ ) was incubated for $120 \mathrm{~min}$ at $30^{\circ} \mathrm{C}$ with GSK-3 $\beta$ (approx. $50 \mathrm{ng}$ ) and $5 \mu \mathrm{m}\left[\gamma^{-32} \mathrm{P}\right]$ ATP $(500 \mathrm{cpm} / \mathrm{pmol}$ ) in the presence of either $10 \mu \mathrm{m}$ compound A, $10 \mu \mathrm{m}$ compound C, $10 \mu \mathrm{m}$ compound $\mathrm{E}$ or $3 \mu \mathrm{M}$ EGCG, ${ }^{32} \mathrm{P}$-labelled bMBP was digested with trypsin in the gel, and the resulting fragments were detected, as described in the legend of Fig. 9.

(a) rhTP

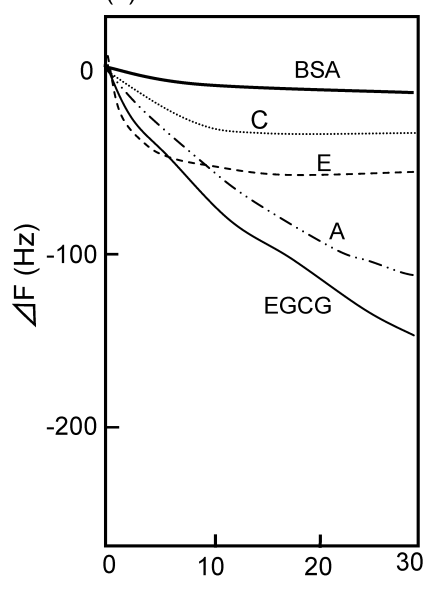

(b) bMBP

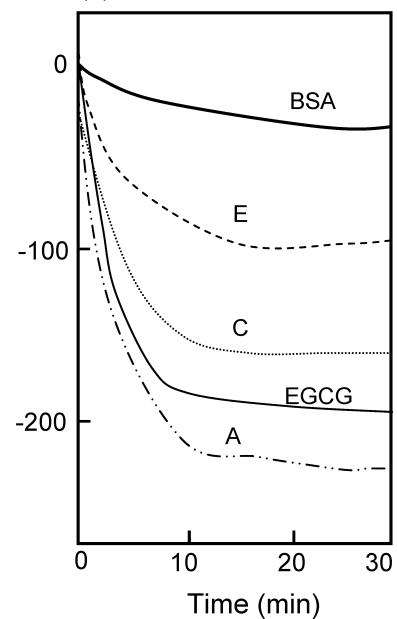

(c) rCRMP-2

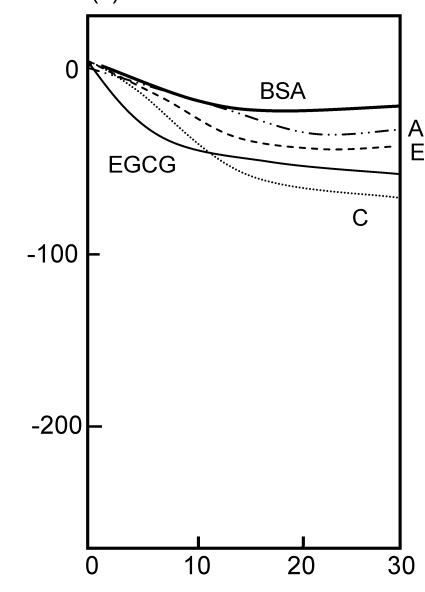

Fig. 11. Binding Affinities of the Three Taxus Compounds with Three Substrate Proteins (bMBP, rhTP and rCRMP-2) in Vitro

The binding affinities of two basic proteins [rhTP (a) and bMBP (b)], an acidic protein [rCRMP-2 (c)] and BSA (control protein) with one of three Taxus compounds (A, $\mathrm{C}, \mathrm{E})$ at $10 \mu \mathrm{M}$ in comparison with $3 \mu \mathrm{M}$ EGCG were separately determined at $30^{\circ} \mathrm{C}$, using a QCM in $8 \mathrm{~mL}$ of $40 \mathrm{~mm}$ Tris- $\mathrm{HCl}(\mathrm{pH} 7.6)$.

in vitro (Fig. 12). Further analytical studies on the GSK-3 $\beta$ mediated high phosphorylation of rhTP primed by at least two TP-kinases (CK1 $\delta$ and novel $\operatorname{PKC} \delta(\mathrm{nPKC} \delta)$ ), using these two Taxus ligans and EGCG as selective high stimulators for GSK-3 $\beta$, may provide direct evidence to explain the biochemical process and the regulatory mechanism in the GSK- $3 \beta$ mediated hyperphosphorylation of TP primed by these two TP-kinases in an early stage of AD.

The binding abilities of these three Taxus compounds with three brain proteins (bMBP, rhTP and rCRMP-2) (Fig. 11) did not correspond their stimulatory and inhibitory effects on the GSK-3 $\beta$-mediated phosphorylation of these substrate proteins in vitro (Figs. 2, 4, 5). The findings that these three Taxus compounds induce the novel potent phosphorylation sites for GSK-3 $\beta$ on these two basic brain proteins (Figs. 9, 10), suggest that the direct binding of these Taxus compounds to them may induce the conformational changes, which presumably expose the novel potent phosphorylation sites for GSK- $3 \beta$ in vitro. In contrast, tanegool at a low dose $\left(\mathrm{IC}_{50}=\right.$ approx. $\left.1 \mu \mathrm{M}\right)$ inhibited the GSK-3 $\beta$-mediated phosphorylation of rCRMP-2 (Fig. 5), which had a low binding affinity with the Taxus compound in vitro (Fig. 11). Since tanegool reduces the apparent $K_{\mathrm{m}}$ values of two substrates (rCRMP-2 and ATP) for GSK-3 $\beta$ (data not shown), it seems like that the direct binding of tanegool to GSK-3 $\beta$ may inhibit the enzymatic reaction of the kinase with its two substrates (rCRMP-2 and ATP) in vitro. In the case of 


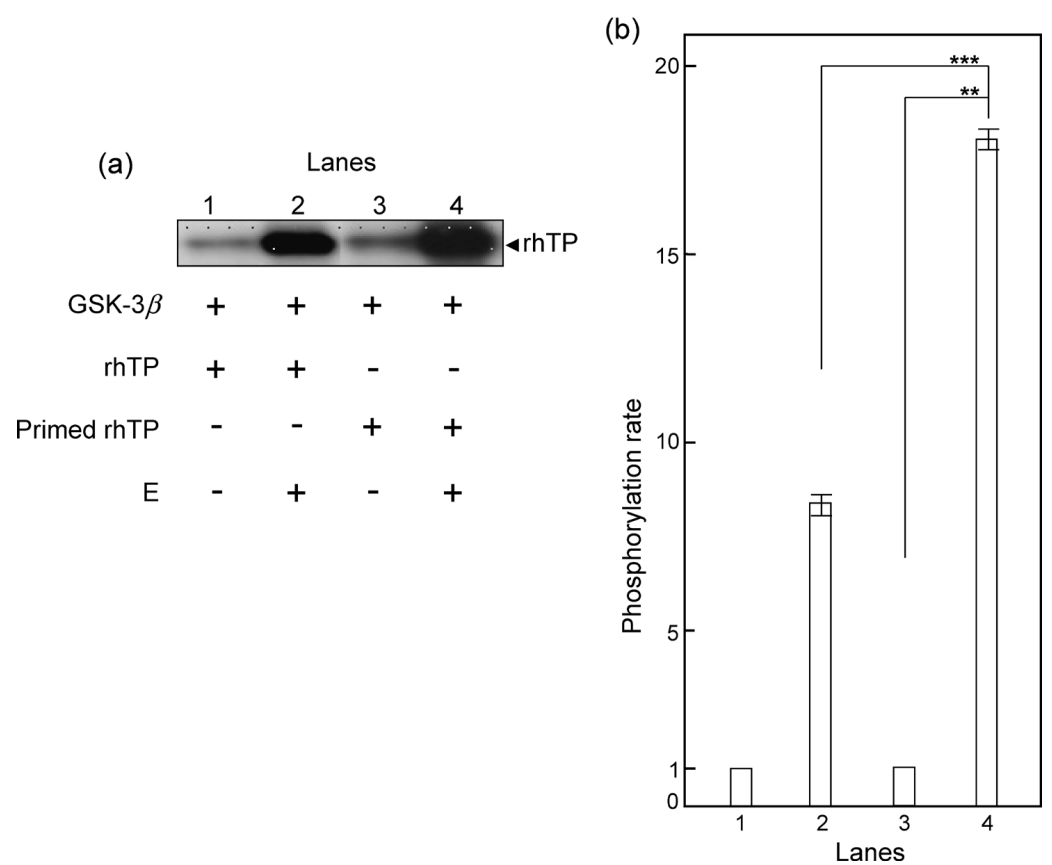

Fig. 12. The High Substrate Activity of rhTP Primed by CK1 $\delta$ for GSK-3 $\beta$ in the Presence of Compound E in Vitro

(a) rhTP (approx. $1 \mu \mathrm{g}$ ) previously fully phosphorylated by CK1 $\delta$ (approx. 5 units) for $120 \mathrm{~min}$ at $30^{\circ} \mathrm{C}$ using cold ATP was used as a phosphate acceptor for GSK-3 $\beta$ in vitro. Either unprimed rhTP (lanes 1 and 2) or primed rhTP (lanes 3 and 4) was further incubated for $20 \mathrm{~min}$ at $30^{\circ} \mathrm{C}$ with GSK-3 $\left(\right.$ approx. $50 \mathrm{ng}$ ) and $5 \mu \mathrm{M}\left[\gamma_{-}{ }^{32} \mathrm{P}\right] \mathrm{ATP}$ $(500 \mathrm{cpm} / \mathrm{pmol}$ ) in the absence (lanes 1 and 3) or presence (lanes 2 and 4) of $10 \mu \mathrm{m}$ compound E. This phosphorylation was arrested by the addition of SDS-sample buffer, ${ }^{32} \mathrm{P}$-labelled unprimed rhTP or primed rhTP in the reaction mixtures was detected by autoradiography after SDS-PAGE. (b) Mean values obtained from the autoradiogram (Fig. 12a) by scanning with a spectrophotometer. The rate 1 represents the GSK-3 $\beta$-mediated phosphorylation of unprimed rhTP (lane 1) and primed rhTP (lane 3) in the absence of compound $\mathrm{E}$ in vitro. ${ }^{*} p<0.01$, primed rhTP in the absence of compound $\mathrm{E} ;{ }^{* * *} p<0.01$, unprimed rhTP (lane 2) compared with primed rhTP (lane 4).

EGCG, this polyphenol compound may preferentially bind to the domains, containing the potent phosphorylation sites for GSK-3 $\beta$ on rCRMP-2, as previously reported.) However, the physiological significance of the EGCG-induced selective inhibition for the GSK-3 $\beta$-mediated phosphorylation of CRMP-2 at the cellular level is not yet elucidated in present.

To clearly understand the biological significance of three effective Taxus lignans [(3S,4R)-4'-hydroxy-6,3'-dimethoxyisoflavan-4-ol, (7R)-7-hydroxytaxiresinol and tanegool] on the GSK-3 $\beta$-mediated high phosphorylation of two basic proteins (MBP and TP) and an acidic protein (CRMP-2), further analytical studies are required to (i) determine the novel consensus Taxus lignan-binding domains, containing at least one potent phosphorylation site (Ser-residue) for GSK-3 $\beta$ on TP and MBP; (ii) characterize novel Taxus lignans as potent selective inhibitors for the GSK-3 $\beta$-mediated phosphorylation of CRMP-2 (a microtubule-binding protein involved in the axon outgrowth of neurons) in normal neuron; (iii) detect their binding novel functional proteins preferentially phosphorylated by GSK-3 $\beta$ in the brain of AD model mouse; and (iv) elucidate the novel effects of these three Taxus lignans on the GSK- $3 \beta$-mediated regulation of TP with its associated proteins, containing multiple potent phosphorylation sites for $\mathrm{CK} 1 \delta$ and $\mathrm{nPKC} \delta$, in neuronal cell function. ${ }^{21,27)}$ After these analytical studies, it should be possible to (i) explain the biological and pharmacological significances of novel Taxus lignans on the GSK- $3 \beta$-mediated regulation of TP with its associated functional proteins ${ }^{21)}$ and a native novel substrate $\beta$-adducin $(80 \mathrm{kDa}, \mathrm{p} I=5.67)^{28)}$ involved in cell differentiation and morphological development of neuron; and (ii) elucidate the biochemical mechanisms of anti-inflammatory, ${ }^{10)}$ antiproliferation of cancer cell ${ }^{17)}$ and neuroprotective effects ${ }^{17)}$ in- duced by these Taxus lignans at the cellular level.

Acknowledgments This work was supported by in part by Grants from the Graduate School of Medical Sciences, Kitasato University (2009-2010). We are grateful to Dr. Fumitaka Kawakami (Kitasato University) for his technological supports and valuable discussion in this study, and to Dr. Ian Gleadall for correction of English and critical comments on the manuscript.

\section{REFERENCES}

1) Miyai S, Yamaguchi A, Iwasaki $T$, Shamsa $F$, Ohtsuki $K$. Biochemical characterization of epigallocatechin-3-gallate as an effective stimulator for the phosphorylation of its binding proteins by glycogen synthase kinase-3 $\beta$ in vitro. Biol. Pharm. Bull., 33, 1932-1937 (2010).

2) Kawakami F, Yamaguchi A, Suzuki K, Yamamoto T, Ohtsuki K. Biochemical characterization of phospholipids, sulfatide and heparin as potent stimulators for autophosphorylation of GSK- $3 \beta$ and the GSK-3 $\beta$-mediated phosphorylation of myelin basic protein in vitro. J. Biochem., 143, 359-367 (2008).

3) Woodgett JR. Molecular cloning and expression of glycogen synthase kinase-3/factor A. EMBO J., 9, 2431-2438 (1990).

4) Ali A, Hoeflich KP, Woodgett JR. Glycogen synthase kinase-3: properties, functions, and regulation. Chem. Rev., 101, 2527-2540 (2001).

5) Soutar MPM, Kim WY, Williamson R, Peggie M, Hastie CJ, McLauchlan H, Snider WD, Gordon-Weeks PR, Sutherland C. Evidence that glycogen synthase kinase-3 isoforms have distinct substrate preference in the brain. J. Neurochem., 115, 974-983 (2010).

6) Frame S, Cohen P. GSK3 takes centre stage more than 20 years after its discovery. Biochem. J., 359, 1-16 (2001). 
7) Rayasam GV, Tulasi VK, Sodhi R, Davis JA, Ray A. Glycogen synthase kinase 3: more than a namesake. Br. J. Pharmacol., 156, 885-898 (2009)

8) Lochhead PA, Kinstrie R, Sibbet G, Rawjee T, Morrice N, Cleghon V. A chaperone-dependent GSK $3 \beta$ transitional intermediate mediates activation-loop autophosphorylation. Mol. Cell, 24, 627-633 (2006).

9) Phukan S, Babu VS, Kannoji A, Hariharan R, Balaji VN. GSK3 $\beta$ : role in therapeutic landscape and development of modulators. $B r . J$. Pharmacol., 160, 1-19 (2010).

10) Nguyen NT, Banskota AH, Tezuka Y, Nobukawa T, Kadota S. Diterpenes and sesquiterpenes from the bark of Taxus yunnanensis. Phytochemistry, 64, 1141-1147 (2003).

11) Banskota AH, Tezuka Y, Nguyen NT, Awale S, Nobukawa T, Kadota S. DPPH radical scavenging and nitric oxide inhibitory activities of the constituents from the wood of Taxus yunnanensis. Planta Med., 69, 500-505 (2003).

12) Nguyen NT, Banskota AH, Tezuka Y, Le Tran Q, Nobukawa T, Kurashige Y, Sasahara M, Kadota S. Hepatoprotective effect of taxiresinol and $\left(7^{\prime} R\right)-7^{\prime}$-hydroxylariciresinol on D-galactosamine and lipopolysaccharide-induced liver injury in mice. Planta Med., 70 , 29-33 (2004).

13) Banskota AH, Nguyen NT, Tezuka Y, Nobukawa T, Kadota S. Hypoglycemic effects of the wood of Taxus yunnanensis on streptozotocin-induced diabetic rats and its active components. Phytomedicine, 13, 109-114 (2006).

14) Yin J, Tezuka Y, Subehan, Shi L, Nobukawa M, Nobukawa T, Kadota S. In vitro anti-osteoporotic activity of isotaxiresinol, a lignan from wood of Taxus yunnanensis. Phytomedicine, 13, 37-42 (2006).

15) Koyama J, Morita I, Kobayashi N, Hirai K, Simamura E, Nobukawa T, Kadota S. Antiallergic activity of aqueous extracts and constituents of Taxus yunnanensis. Biol. Pharm. Bull., 29, 2310-2312 (2006).

16) Ueda J, Awale S, Tezuka Y, Shimamura E, Hirai K, Nobukawa T, Sato A, Kadota S. Growth inhibitory activity of wood of Taxus yunnanesis and its liquid chromatography Fourier-transform mass pectrometry anakysis. Planta Med., 72, 1241-1244 (2006).
17) Tezuka Y, Morikawa K, Li F, Auw L, Awale S, Nobukawa T, Kadota S. Cytochrome P450 3A4 inhibitory constituents of the wood of Taxus yunnanensis. J. Nat. Prod., 74, 102-105 (2011).

18) Macías FA, López A, Varela RM, Torres A, Molinillo JMG. Bioactive lignans from a cultivar of Helianthus annuus. J. Agric. Food Chem., 52, 6443-6447 (2004).

19) Miller RW, Mctaughlin JL, Powell RG, Plattner RD. Weisleder D Jr, Smitth CR, Lignans from Taxus wallichiana. J. Nat. Prod., 45, $78-83$ (1982).

20) Kawakami F, Suzuki K, Ohtsuki K. A novel consensus phosphorylation motif in sulfatide- and cholesterol-3-sulfate-binding protein substrates for CK1 in vitro. Biol. Pharm. Bull., 31, 193-200 (2008).

21) Suzuki K, Kawakami F, Sasaki H, Maruyama H, Ohtsuki K. Biochemical characterization of tau protein and its associated syndapin 1 and protein kinase $\mathrm{C} \varepsilon$ for their functional regulation in rat brain. Biochim. Biophys. Acta, 1790, 188-197 (2009).

22) Wang QM, Fiol CJ, DePaoli-Roach AA, Roach PJ. Glycogen synthase kinase- $3 \beta$ is a dual specificity kinase differentially regulated by tyrosine and serine/threonine phosphorylation. J. Biol. Chem., 269, 14566-14574 (1994).

23) Hooper C, Killick R, Lovestone S. The GSK3 hypothesis of Alzheimer's disease. J. Neurochem., 104, 1433-1439 (2008).

24) Yasojima K, Kuret J, DeMaggio AJ, McGeer E, McGeer PL. Casein kinase $2 \delta$ mRNA is upregulated in Alzheimer disease brain. Brain Res., 865, 116-120 (2000).

25) Avila J, Lucas JJ, Perez M, Hernandez F. Role of tau protein in both physiological and pathological conditions. Physiol. Rev., 84, 361-384 (2004).

26) Garcia-Segura LM, Sanz A, Mendez P. Cross-talk between IGF-I and estradiol in the brain: focus on neuroprotection. Neuroendocrinology, 84, 275-279 (2006).

27) Kannanayakal TJ, Tao H, Vandre DD, Kuret J. Casein kinase-1 isoforms differentially associate with neurofibrillary and granulovacuolar degeneration lesions. Acta Neuropathol., 111, 413-421 (2006).

28) Farghaian H, Turnley AM, Sutherland C, Cole AR. Bioinformatic prediction and confirmation of $\beta$-adducin as a novel substrate of glycogen synthase kinase 3. J. Biol. Chem., 286, 25274-25283 (2011). 